\section{Efeito do tempo e da temperatura de estocagem nas determinações de acidez, cálcio, proteínas e lipídeos de leite de doadoras de bancos de leite humano}

\section{Effect of storage time and temperature on the acidity, calcium, protein and lipid content of milk from human milk banks}

Maria Stella S. Rona 1

Franz Reis Novak 2

Márcia Portilho 3

Francieli Maria Pelissari 4

Ana Beatriz Tozzo Martins 5

Graciette Matioli 6

1 Hospital Universitário. Universidade Estadual de Maringá Maringá, PR, Brasil.

2 Instituto Fernandes Figueira. Rio de Janeiro, RJ, Brasil.

3,6 Departamento de Farmácia e Farmacologia. Universidade Estadual de Maringá. Av. Colombo, 5790, Bloco P02. Maringá, PR, Brasil. CEP: 87.020-900. E-mail: gmatioli@uem.br

4 Departamento de Engenharia de Alimentos. Universidade Estadual de Maringá. Maringá, PR, Brasil.

5 Departamento de Estatística. Universidade Estadual de Maringá Maringá, PR, Brasil.

\section{Resumo}

Objetivos: verificar o efeito de três condições de estocagem sobre a acidez do leite humano ordenhado, bem como determinar os seguintes constituintes do leite: gordura, sólidos totais, cinzas, cálcio e proteinas totais.

Métodos: as amostras foram obtidas a partir de doadoras do Banco de Leite Humano do Hospital Universitário de Maringá, Paraná, Brasil (n=37). Foram determinados os conteúdos de gordura, proteina, sólidos totais, cinzas e cálcio, além da determinação da acidez. O protocolo de pesquisa incluiu três condições de estocagem: tempo zero, 4 hà temperatura ambiente e $24 \mathrm{~h}$ sob refrigeração

Resultados: as concentrações médias de nutrientes encontradas eram comparáveis àquelas descritas em leite de nutrizes de outros países ou de outras regiões do país e adequadas para a alimentação de recém-nascidos. Os dados de acidez demonstraram alta variabilidade interindividual para as condições de estocagem à 4 he 24h, o que não aconteceu na estocagem imediata (0h). Observou-se fraca correlação entre as variáveis acidez e concentração de proteína, bem como entre acidez e teor de cálcio.

Conclusões: a acidez não influenciou a concentração desses nutrientes, nas condições de estocagem estudadas, e que a melhor forma de se preservar o leite humano foi congelá-lo imediatamente após sua obtenção.

Palavras-chave Aleitamento materno, Controle de qualidade, Leite humano, Valor nutritivo 


\section{Introdução}

O desenvolvimento populacional demanda a produção de novas tecnologias para garantir tanto a qualidade quanto a quantidade de alimento para a população, isso se reflete nos recém-nascidos prematuros, onde a qualidade do alimento é fundamental para sua sobrevivência, devido aos benefícios nutricionais, de proteção e os aspectos tróficos gastrointestinais. ${ }^{1-3}$

As estratégias "Dez Passos para o Aleitamento Materno" e a "Iniciativa Hospital Amigo da Criança", criados pela Organização Mundial da Saúde e pelo fundo das Nações Unidas para Infância (UNICEF), ${ }^{4}$ são iniciativas criadas para estimular a prática de aleitamento materno na população em geral.

Visando reduzir as perdas de leite humano em decorrência do desmame precoce, incentivou-se a implantação de Bancos de Leite Humano, definidos pela Secretaria de Políticas de Saúde do Ministério da Saúde e a Fundação Oswaldo Cruz, como:

Centros especializados, responsáveis pela promoção e incentivo ao aleitamento materno e execução de atividades de coleta, processamento e controle de qualidade de colostro, leite de transição e leite humano maduro, para posterior distribuição a uma população vulnerável que deles dependem como fator de sobrevivência (1998: 9). ${ }^{1}$

O leite materno é a única e principal fonte de cálcio para a criança nos primeiros meses de vida. Esse mineral desempenha funções fisiológicas tão importantes para a sobrevivência, que em casos de deficiência dietética grave ou de perdas anormais os mecanismos envolvidos no seu controle chegam a desmineralizar os ossos para manter os níveis de cálcio dentro da normalidade. Após o nascimento cessa-se bruscamente a oferta de cálcio para o recém-nascido, ocorrendo uma redução progressiva nas concentrações de cálcio sérico e iônico. Sua absorção depende de vários fatores, entre eles a relação cálcio/fósforo, ideal no leite materno. ${ }^{5}$ Problemas na coleta ou a má conservação do leite ordenhado podem levar a uma acidez progressiva que desestabiliza as micelas de caseína, liberando fósforo e cálcio que unem as frações das micelas levando a uma indisponibilidade do cálcio. 5

$\mathrm{Na}$ primeira semana pós-parto é sintetizado o colostro, rico em fatores de proteção, especialmente imunoglobulina secretória A (IgAs), que agem contra infecções e reduzem as alergias alimentares. O leite maduro produzido a partir do $15^{\circ}$ dia pósparto, por sua vez, contém mais proteínas nutritivas que o colostro, como as caseínas e as proteínas do soro ( $\alpha$-lactoalbumina, lactoferrina, lisozima, albumina sérica e as imunoglobulinas $\mathrm{A}, \mathrm{G}$ e $\mathrm{M}$ ), que representam $72 \%$ e $28 \%$ da proteína total do leite, respectivamente. ${ }^{2}$

A qualidade do leite humano ordenhado pode ser definida como uma grandeza que resulta da avaliação conjunta de uma série de parâmetros, que incluem as características nutricionais, imunológicas, químicas e microbiológicas. O Programa Nacional de Controle de Qualidade em Banco de Leite Humano, criado pelo Governo Federal em 2003 , visa garantir a qualidade do processamento do leite coletado e distribuído. 6

Por ser um produto lábil, a coleta do leite e sua conservação precisam ser rigorosamente controladas para a manutenção de sua qualidade, pois o leite se altera facilmente com o calor e a proliferação de microrganismos, especialmente em presença daqueles que degradam a lactose com produção de ácidos. Segundo Galhardo et al.,7 durante o armazenamento do leite ocorre oxidação lipídica, que pode ser detectada através da determinação da acidez titulável. Esses autores também verificaram que essa acidez varia em leites de diferentes doadoras e em diferentes amostras da mesma doadora. 6,7

A água é o componente mais abundante do leite humano $(87,5 \%)$, resultando em baixa carga de soluto quando comparado ao leite de vaca, e desempenha papel fundamental na regulação da temperatura corporal do recém-nascido. $3,6,8$

O leite humano fornece todos os aminoácidos essenciais e não-essenciais, vitaminas e minerais que os recém-nascidos necessitam. Os lipídeos estão presentes na forma de emulsão e aumentam com o tempo de lactação, chegando a fornecer cerca de $50 \%$ da energia do leite. Além disso, o leite humano é a única ou a principal fonte de cálcio para a criança nos primeiros meses de vida. $2,3,6,8,9$

Os critérios de conservação de leite humano estabelecidos pelo Ministério da Saúde incluem três condições de estocagem: congelamento imediato, até quatro horas à temperatura ambiente e 24 horas sob refrigeração. Considerando que o aumento da acidez pode levar a uma desestabilização das micelas de caseína e, conseqüentemente, a liberação de fósforo e cálcio, reduzindo a disponibilidade dos mesmos, o objetivo do presente trabalho foi verificar o efeito de três condições de estocagem sobre a acidez do leite humano ordenhado. Também foram feitas determinações de constituintes do leite, tais como gordura, sólidos totais, cinzas, cálcio e proteínas totais. 


\section{Métodos}

Foram coletadas amostras de doadoras do Banco de Leite Humano do Hospital Universitário de Maringá, Paraná, sendo selecionadas aquelas com maiores volumes de leite doado.

A média mensal de doadoras no ano de 2003 foi de 40 nutrizes este foi o número de amostras analisadas com as doadoras do mês de maio de 2004. O período da pesquisa deu-se de maio a agosto do mesmo ano. Considerando que no presente estudo foram utilizadas apenas amostras de leite humano ordenhado maduro, três amostras analisadas não foram incluídas nos resultados por apresentarem tempo de lactação inferior a 15 dias.

O protocolo de pesquisa foi aprovado pelo Comitê de Ética da Universidade Estadual de Maringá. As doadoras selecionadas foram informadas sobre o conteúdo da pesquisa e obtido o consentimento livre e esclarecido, através de documento assinado.

As coletas foram realizadas pelas próprias doadoras, no domicílio, através de ordenha manual, seguindo método adotado pelos bancos de leite 1 e na presença de um dos autores do trabalho. $\mathrm{O}$ volume coletado de cada doadora foi de $50 \mathrm{~mL}$ em frascos de vidro esterilizados. Imediatamente após a coleta, ainda na casa da doadora, o leite foi submetido a um resfriamento rápido com auxílio de um banho criogênico de álcool etílico $70 \%(\mathrm{v} / \mathrm{v})$ a $-20^{\circ} \mathrm{C}$. Posteriormente, foi transportado ao laboratório sob refrigeração, em caixa térmica com temperatura entre dois e cinco graus, não ultrapassando um período de uma hora até o destino.

No laboratório, cada amostra foi pipetada, em campo de chama, para nove tubos de ensaio (16 $\mathrm{x}$ $160 \mathrm{~mm}$ ) com tampa rosqueável e previamente autoclavados. Os tubos foram identificados conforme as análises a serem realizadas e as amostras de leite congeladas.

O estudo foi baseado em três diferentes condições de estocagem, conforme os trabalhos de Hamosh et al. 10 e a recomendação do Ministério da Saúde: ${ }^{1}$ a) alíquotas congeladas $\left(-20^{\circ} \mathrm{C}\right)$ imediatamente após a coleta (tempo zero); b) alíquotas que permaneceram à temperatura ambiente $\left(25\right.$ a $\left.28^{\circ} \mathrm{C}\right)$ por $4 \mathrm{~h}$ e, imediatamente, congeladas; c) alíquotas refrigeradas a temperatura de geladeira $\left(6\right.$ a $\left.8^{\circ} \mathrm{C}\right)$ por 24 h e, então, congeladas.

Todas as alíquotas foram submetidas as seguintes determinações: acidez, proteína, gordura, sólidos totais, cinzas e cálcio, e ficaram congeladas por um tempo máximo de 15 dias até a análise.

A acidez desenvolvida foi avaliada, em triplicata, utilizando-se uma solução de hidróxido de sódio N/9 (solução Dornic) para neutralizar a acidez de $1 \mathrm{~mL}$ de amostra de leite humano ordenhado, tendo como indicador a fenolftaleína em solução hidroalcoólica a $1 \%$. A análise foi realizada com o auxílio de um microacidímetro Dornic. 11

O teor de gordura foi determinado através da técnica do crematócrito descrita por Lucas et al. 12 As amostras previamente descongeladas foram aquecidas em banho-maria a $40^{\circ} \mathrm{C}$, homogeneizadas em vortex por 15 segundos, para posterior transferência para tubos capilares (em triplicata) e centrifugadas a $12.000 \mathrm{x}$ g por 15 minutos em centrífuga para microhematócrito CELM, com capacidade para 24 capilares. A camada de creme e a coluna total foram medidas em milímetros com auxílio de um paquímetro.

A porcentagem de creme, de gordura e o conteúdo energético foram calculados utilizando-se as expressões: 13

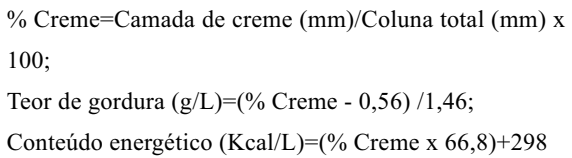

A determinação de sólidos totais foi realizada transferindo-se $3 \mathrm{~mL}$ de leite para um cadinho de porcelana e aquecendo-se em estufa a $80^{\circ} \mathrm{C}$ por 14 horas. O material foi pesado e os sólidos totais expressos em g/L. 14

As cinzas foram determinadas pela carbonização lenta das amostras em fogo direto, incineração em mufla à $550^{\circ} \mathrm{C}$ por 12 horas, seguida de pesagem. $\mathrm{O}$ resultado foi expresso em g/L. 14

Para quantificação de cálcio, as cinzas obtidas no item anterior foram dissolvidas em $3 \mathrm{~mL}$ de $\mathrm{HCl} 1,2$ $\mathrm{mol} / \mathrm{l}$ e transferidas para tubos de polipropileno. Foi utilizado um kit comercial (Labtest, Minas Gerais) e as determinações realizadas por técnica colorimétrica. 15 Partindo-se de $1 \mathrm{~mL}$ do reagente de trabalho do kit, adicionava-se $20 \mu \mathrm{L}$ da amostra (solução de cinzas), homogeneizando em vortex. Após esse procedimento, determinou-se o valor de absorbância (Abs) a $570 \mathrm{~nm}$ e efetuou-se o cálculo com auxílio da seguinte equação. 14

Cálcio $(\mathrm{mg} / \mathrm{L})=($ Abs da amostra/Abs do padrão $) \times 100$

$\mathrm{Na}$ determinação das proteínas totais, o leite desengordurado, obtido por centrifugação das amostras a $1500 \mathrm{x}$ g por 20 minutos, 16 foi diluído 1:10 em água destilada. Para eliminar a interferência de compostos não-protéicos, principalmente a 
lactose, a cada $0,5 \mathrm{~mL}$ da amostra diluída foi adicionado $25 \mu \mathrm{L}$ de deoxicolato de sódio a $2,5 \%$ e 1 $\mathrm{mL}$ de ácido tricloroacético a $20 \%$, com homogeneização após cada adição. Depois de 30 minutos à temperatura ambiente, a mistura foi centrifugada a $4500 \mathrm{x}$ g por 15 minutos. O precipitado foi ressuspenso em $1 \mathrm{~mL}$ de água destilada e a proteína determinada pelo método de Lowry et al. 17 modificado. Foi utilizada caseína (0 a $1 \mathrm{mg} / \mathrm{mL}$; Sigma) como padrão. ${ }^{14}$

As análises estatísticas incluíram: análise descritiva, teste de Friedman e análise de correlação linear. O software Statística 6.0/2001 (Stat Soft, Inc. Tulsa, OK, EUA) foi utilizado. O teste de Friedman foi realizado com o objetivo de verificar a existência de diferença significativa entre os tempos 0,4 e 24 horas. Em seguida, utilizou-se o método para comparação individual entre os tratamentos (tempos) denominado Comparações Múltiplas para a localização das possíveis diferenças entre os pares de tempos. 18,19 Através da análise de correlação linear buscou-se verificar a possível correlação entre as variáveis acidez e proteína, assim como acidez e cálcio. O nível de significância considerado foi de $5 \% .18$

\section{Resultados}

Entre as 37 doadoras voluntárias, 8 (20\%) estavam no início da lactação (entre 16 e 30 dias pós-parto) e as demais entre 31 e 180 dias pós-parto. Do total, 30 (75\%) apresentavam idade gestacional acima de 39 semanas (a termo) e 7 eram pré-termo (de 34 a 38 semanas).
As concentrações de nutrientes das amostras $(\mathrm{n}=35$ para sólidos totais e cinzas, e $\mathrm{n}=37$ para as demais determinações) estocadas em três diferentes condições (congelamento em tempo zero, $4 \mathrm{~h}$ à temperatura ambiente e $24 \mathrm{~h}$ sob refrigeração) estão apresentadas na Tabela 1.

Observou-se, através do coeficiente de variação (CV), que nenhuma das amostras apresentou alta variabilidade na concentração de seus constituintes, contudo, os teores de gordura e cinzas apresentaram variabilidade maior que as demais variáveis.

Com relação aos sólidos totais e, especialmente, o cálcio, a variabilidade na concentração foi a menor observada, nas três condições de estocagem estudadas.

Foi realizado o teste de Friedman para proteína e cálcio. Com relação à proteína, houve diferença significativa $(p<0,05)$ e o método de comparações múltiplas constatou essa diferença somente entre a estocagem zero e $24 \mathrm{~h}$. Para o cálcio não houve diferença estatisticamente significativa entre as condições de estocagem estudadas $(p>0,05)$

A Tabela 2 apresenta os dados de acidez referentes às amostras nas três diferentes condições de estocagem estudadas. Foi observada alta variabilidade na acidez Dornic entre as amostras nos tempos de 4 e $24 \mathrm{~h}$ (CV acima de 50\%, em ambos os casos), o que não aconteceu no tempo de zero hora $(\mathrm{CV}=27 \%)$. Foi realizado o teste de Friedman para acidez e foi observada diferença estatisticamente significativa ao nível de $5 \%(p<0,05)$. O método de comparações múltiplas verificou essa diferença entre todas as condições de estocagem estudadas $(0$ e $4 \mathrm{~h}$; 0 e $24 \mathrm{~h} ; 4$ e $24 \mathrm{~h})$.

Tabela 1

\begin{tabular}{|c|c|c|c|c|c|c|c|c|c|}
\hline \multirow[t]{3}{*}{ Nutriente } & \multicolumn{9}{|c|}{ Tempo (horas) } \\
\hline & \multicolumn{3}{|c|}{ Zero } & \multicolumn{3}{|c|}{ Quatro } & \multicolumn{3}{|c|}{ Vinte e quatro } \\
\hline & Md & $\bar{X} \pm d p$ & $\mathrm{CV}$ & Md & $\bar{X} \pm d p$ & $\mathrm{CV}$ & $M d^{*}$ & $\bar{X} \pm d p$ & $\mathrm{CV}$ \\
\hline Gordura (g/L) & - & $35,36 \pm 13,77$ & 39 & - & $31,91 \pm 13,36$ & 42 & - & $31,61 \pm 13,41$ & 42 \\
\hline Energia (KcaL) & - & $674,53 \pm 34,46$ & 20 & - & $631,58 \pm 138,33$ & 22 & - & $637,81 \pm 130,83$ & 21 \\
\hline Proteína (g/L) & 5,22 & $5,77 \pm 1,57 b$ & 27 & 5,53 & $5,93 \pm 1,53 a b$ & 26 & 5,96 & $6,08 \pm 1,47 a$ & 24 \\
\hline Sólidos (g/L) & - & $131,37 \pm 12,50$ & 10 & - & $130,73 \pm 13,96$ & 11 & - & $129,87 \pm 12,53$ & 10 \\
\hline Cinzas (g/L) & 2,33 & $2,05 \pm 0,76$ & 37 & - & $2,10 \pm 0,74$ & 35 & - & $2,19 \pm 0,85$ & 39 \\
\hline Cálcio (mg/L) & - & $251,55 \pm 11,88$ & 5 & - & $251,16 \pm 11,61$ & 5 & - & $244,27 \pm 11,30$ & 5 \\
\hline
\end{tabular}

*Letra sobrescrito diferente $=(p<0,05) ; C V=$ coeficiente de variação. 
Tabela 2

Acidez (Dornic) das amostras de leite maduro cru das doadoras do Banco de Leite Humano do Hospital Universitário. Maringá, Paraná, maio 2004.

\begin{tabular}{lcccccc}
\hline Tempo (h) & $\mathbf{n}$ & Min - Max & Md & Média & dp & CV (\%) \\
\hline $0^{*}$ & 37 & $1,00-4,33$ & 2,00 & $2,2432 \mathrm{c}$ & 0,5961 & 27 \\
$4^{* *}$ & 37 & $1,33-11,67$ & 3,00 & $3,5538 \mathrm{~b}$ & 2,3233 & 65 \\
$24 * * *$ & 37 & $1,00-16,33$ & 4,67 & $6,2703 \mathrm{a}$ & 4,0208 & 64 \\
\hline
\end{tabular}

* Congelamento imediato; ** temperatura ambiente; *** sob refrigeração; CV=Coeficiente de variação.

Quanto às correlações da acidez com os nutrientes proteína e cálcio, segundo as três condições de estocagem estudadas, observou-se que não existe correlação linear significativa entre as variáveis acidez e proteína, bem como entre acidez e cálcio $(p>0,05)$.

\section{Discussão}

A concentração de nutrientes do leite humano está sujeita às variações longitudinais e interindividuais, relacionadas tanto com as variações na dieta da nutriz, como durante a coleta da amostra em uma mesma ordenha (leite anterior e posterior) e podem afetar os resultados da composição centesimal do leite humano ordenhado. ${ }^{14}$ Para minimizar tais variações, no presente estudo, foram selecionadas apenas amostras de leite maduro.

Através da comparação da média de valores das concentrações dos nutrientes analisados nesse estudo com as médias dos valores encontrados na literatura de outros países e de outras regiões do Brasil, pôdese observar que as concentrações de proteínas $(8,18$ $\mathrm{g} / \mathrm{L})$, gorduras $(33,4 \mathrm{~g} / \mathrm{L})$, sólidos totais $(143,4 \mathrm{~g} / \mathrm{L})$, cálcio $(229,5 \mathrm{mg} / \mathrm{L})$ e cinzas $(2,15 \mathrm{~g} / \mathrm{L})$, além da energia $(649 \mathrm{Kcal} / \mathrm{L})$, encontravam-se dentro da faixa de valores descritos. ${ }^{14,20-25}$

As concentrações de sólidos totais e cinzas permaneceram inalteradas nas três condições de estocagem estudadas. Em média, a concentração de sólidos totais variou de $129,9 \mathrm{~g} / \mathrm{L}$ a $131,4 \mathrm{~g} / \mathrm{L}$, enquanto para as cinzas o valor variou entre $2,05 \mathrm{e}$ $2,19 \mathrm{~g} / \mathrm{L}$. Esses valores estão compatíveis com os obtidos por Trugo et al. 21

É amplamente conhecido que a gordura no leite humano sofre variabilidade interindividual e longitudinal,22,26,27 como a encontrada nas amostras analisadas (próximo a 40\%). Isto representa a variabilidade interindividual desse nutriente no leite e a variação longitudinal de suas concentrações dentro das diferentes condições de estocagem estudadas. Essa variabilidade pode ser resultado das características individuais das doadoras, estágio de lactação, perdas durante a estocagem (aderência de nutrientes ao frasco de coleta) e amostra de leite (leite de início ou final de mamada, hora do dia e momento da coleta). 22

Segundo Koletzko e Rodriguez-Palmeo,28 a gordura contribui com mais de $55 \%$ do conteúdo energético não-protéico e contém ácidos graxos $\omega-3$ de cadeia muito longa (20:5 $\omega-3$ e $22: 6 \omega-3)$, essenciais para o desenvolvimento do recém-nascido, os quais não podem ser sintetizados em quantidades adequadas a partir do ácido $\alpha$-linolênico (18:3 $\omega$-3) por recém-nascidos pré-termo e termo.

Nesse estudo não foram verificadas as variações na concentração de gordura ao longo do dia, mas alguns autores têm relatado que entre sete e dez horas da manhã a concentração é maior, contudo esses dados não foram significativos. ${ }^{22}$ Para LammiKeefe et al.29 não existe diferença na concentração de gordura ao longo do dia, de acordo com o encontrado em suas pesquisas.

$\mathrm{O} \mathrm{pH}$ do leite humano é levemente alcalino, ficando em torno de 7,0 e representa a acidez atual do leite, dela dependendo propriedades importantes, como a estabilidade da caseína. A má conservação do leite, após a coleta, pode levar a uma acidez progressiva, e essa, por sua vez, desestabilizar as micelas de caseína. Com o aumento na acidez, estas ligações são rompidas e o cálcio se torna menos disponível. ${ }^{6}$ Estudos de Covas et al. $3^{30}$ demonstraram que o leite cru, conservado sob refrigeração $\left(4^{\circ} \mathrm{C}\right)$ por quatro dias, sofre reações lipolíticas e proteolíticas, as quais liberam ácidos graxos e aminoácidos livres, ocasionando o abaixamento do $\mathrm{pH}$. Também Galhardo et al. ${ }^{7}$ sugeriram que a acidez titulável não está somente relacionada com a qualidade higiênicosanitário, mas à oxidação lipídica que ocorre durante $o$ armazenamento.

A acidez desenvolvida no leite resulta do ácido lático e de outros ácidos, provenientes da degradação da lactose pela ação dos microorganismos e, even- 
tualmente, dos lipídeos no leite em vias de alteração. Em condições normais, a acidez Dornic no leite humano varia de 2 a $7^{\circ}$ D. ${ }^{1}$ Segundo recomendações do Ministério da Saúde, ${ }^{1}$ o leite para ser administrado ao recém-nascido não deve apresentar acidez superior a $8^{\circ} \mathrm{D}$.

A acidez apresentou uma alta variabilidade entre as amostras estocadas por $4 \mathrm{~h}$ à temperatura ambiente e por $24 \mathrm{~h}$ sob refrigeração (Tabela 2). Considerando trabalho descrito por Hamosh et al., 5 tal fato pode ser atribuído ao crescimento de diferentes microrganismos psicrotróficos fermentadores da lactose nas amostras analisadas. Portanto, a alta variabilidade observada nas duas situações acima citadas deixa evidente a necessidade de se congelar o leite humano imediatamente após sua coleta. Covas et

\section{Referências}

1. Brasil. Ministério da Saúde. Secretaria de Políticas de Saúde. Instituto Fernandes Figueira da Fundação Oswaldo Cruz. Recomendações técnicas para o funcionamento de bancos de leite humano. 3. ed. Brasília, DF; 1998.

2. Schanler RJ. Suitability of human milk for the low-birthweight infant. Clin Perinatol. 1995; 22: 207-22.

3. Lamounier JA, Vieira GO, Gouvêa LC. Composição do leite materno: fatores nutricionais. In: Rego JD, editor Aleitamento materno. São Paulo: Atheneu; 2001. p. 47-58.

4. Lamounier JA, Leão E. Estratégias para aumentar a prática da amamentação. J Pediatr. (Rio J) 1998; 74: 355-6.

5. Hamosh M, Ellis LA, Pollock DR, Henderson TR, Hamosh P. Breastfeeding and the working mother: effect of time and temperature of short-term storage on proteolysis, lipolysis and bacterial growth in milk. Pediatrics. 1996; 97: 492-8.

6. Almeida JAG. Amamentação: um híbrido natureza-cultura. Rio de Janeiro: FIOCRUZ; 1999.

7. Galhardo ANSM, Araújo WMC, Borgo LA. Acidez Dornic como parâmetro de qualidade em bancos de leite humano. Hig Alim. 2002; 16: 16-27.

8. Moura, EC. Nutrição. In: Carvalho, MR, Tamez, RN, editores. Amamentação: bases científicas para a prática profissional. Rio de Janeiro: Guanabara Koogan; 2002. p. 60-87.

9. Mataloun MMGB, Leone CR. Peculiaridades do metabolismo de cálcio e fósforo no período perinatal: análise crítica de literatura. Rev Pediatr. 1998; 20: 332-84.

10. Hamosh M, Henderson TR, Ellis LA, Mao J, Hamosh P. Digestive enzimes in human milk: stability at suboptimal storage temperatures. J Pediatr Gastroenterol Nutr. 1997; 24: 38-43.

11. Silva VG. Normas técnicas para bancos de leite humano: uma proposta para subsidiar a construção de boas práticas [doutorado]. Rio de Janeiro: Instituto Fernandes Figueira da Fundação Oswaldo Cruz; 2004. al. 30 armazenaram leite cru em freezer $\left(-20^{\circ} \mathrm{C}\right)$ durante 15 dias e verificaram uma estabilidade química quase idêntica à obtida com o leite recémextraído. Nos estudos de Hamosh et al.,5,10 o pH do leite abaixou duas unidades quando este foi estocado nas temperaturas de 15,25 e $38^{\circ} \mathrm{C}$ por $24 \mathrm{~h}$. Contudo, alteração na proteína só foi observada no leite estocado à $38^{\circ} \mathrm{C} .5$

\section{Agradecimentos}

Os autores agradecem ao Conselho Nacional de Desenvolvimento Científico e Tecnológico (CNPq) pelo apoio financeiro através do projeto $\mathrm{CNPq} /$ Proc. n. 502997/2003-6.
12. Lucas A, Gibbs JAH, Lyster RL, Baum JD. Crematocrit: simple clinical technique for estimating fat concentration and energy value of human milk. BMJ. 1978; 1: 1018-20.

13. Wang CD, Chu PS, Mellen BG, Shenai JP. Creamatocrit and the nutrient composition of human milk. J Perinatol. 1999; 19: 343-6.

14. Góes HCA, Torres AG, Donangelo CM, Trugo NMF. Nutrient composition of banked human milk in Brazil and influence of processing on zinc distribuition in milk fractions. Nutrition. 2002; 18: 590-4.

15. Gindler EM, King JD. Rapid colorimetric determination of calcium in biologic fluids with methylthymol blue. Am J Clin Pathol. 1972; 58: 376-82.

16. Keller RP, Neville MC. Determination of total protein in human milk: comparison of methods. Clin Chem. 1986; 32 : 120-3.

17. Lowry OH, Rosebrough NJ, Farr AL, Randall RJ. Protein measurement with the folin phenol reagent. J Biol Chem. 1951; 193: 265-75.

18. Conover WJ. Pratical nonparametric statistics. New York: John Wiley; 1999.

19. Campos H. Estatística experimental não-paramétrica. Piracicaba: ESALQ; 1983.

20. Jensen RG, Bitman J, Carlson SE, Couch SC, Hamosh M, Newbwerg DS. In: Jensen RG, editor. Handbook of milk composition. San Diego: Academic Press; 1995. p. 495542 .

21. Trugo NMF, Donangelo CM, Koury JC, Silva MIB, Freitas LA. Concentration and distribution pattern of selected micronutrients in preterm and term milk from urban Brazilian mothers during early lactation. Eur J Clin Nutr. 1988; 42: 497-507.

22. Mayans E, Martell M. Control de calidad de la leche materna. Arch Argent Pediatr. 1999; 97: 109-15.

23. Neville MC. Volume and caloric density of human milk. In: Jensen RG, editor. Handbook of milk composition. Califórnia: Academic Press; 1995. p. 99-113. 
24. Newburg DS, Neubauer SH. Carbohydrates in milks: analysis, quantities and significance. In: Jensen RG, editor. Handbook of milk composition. Califórnia: Academic Press; 1995. p. 273-350

25. Atkinson S, Alston-Mills B, Lonnerdal B, Neville MC Major minerals and ionic constituints of human and bovine milks. In: Jensen RG, editor. Handbook of milk composition. Califórnia: Academic Press; 1995. p. 593-621.

26. Allen JC, Séller RP, Archer P, Neville MC. Studies in human lactation: milk composition and daily secretion rates of macronutrients in the first year of lactation. Am J Clin Nutr. 1991; 54: 69-80

27. Casey CE, Smith A, Zhang P. Microminerals in human and animal milks. In: Jensen RG, editor. Handbook of milk composition. Califórnia: Academic Press; 1995. p. 622-74.

Recebido em 8 de abril de 2006

Versão final apresentada em 9 de agosto de 2007

Aprovado em 24 de abril de 2008
28. Koletzko B, Rodriguez-Palmero M. Polyunsaturated fatty acids in human milk and their role in early infant development. J Mammary Gland Biol Neoplasia. 1999; 4: 269.

29. Lammi-Keefe CJ, Ferris AM, Jensen RG. Changes in human milk at 0600, 1000, 1400, 1800 and 2200h. J Pediatr Gastroenterol Nutr. 1990; 11: 83-6.

30. Covas MC, Alda E, Baeza A, Ferrer L, Ferrandez C. Almacenamiento de leche humana: su influencia em la composición química y desarrollo bacteriano en tres momentos de la lactancia. Arch Argent Pediatr. 2000; 98: 92-98. 